\title{
State-of-the-Art Report on Alkali Silica Reactivity Mitigation Effectiveness Using Different Types of Fly Ashes
}

\author{
Enamur R. Latifee \\ Glenn Department of Civil Engineering, Clemson University, S. Palmetto Blvd., Clemson, SC 29634, USA \\ Correspondence should be addressed to Enamur R. Latifee; erlatifee@gmail.com
}

Received 30 April 2016; Accepted 30 August 2016

Academic Editor: Yew Wei Leong

Copyright ( 2016 Enamur R. Latifee. This is an open access article distributed under the Creative Commons Attribution License, which permits unrestricted use, distribution, and reproduction in any medium, provided the original work is properly cited.

\begin{abstract}
Use of fly ash by percent replacement of cement is considered as one of the most economical and effective methods for mitigating alkali-silica reaction (ASR) related distress in the concrete. However, fly ash has been proven to be somewhat variable in its effectiveness in inhibiting alkali-silica reactivity, principally because its composition depends on the coal properties from which it is derived. Typically class $\mathrm{C}$ fly ashes are not as efficient as class $\mathrm{F}$ ashes due to their higher calcium oxide content. Nevertheless, it is important to find out whether the lime content in the fly ash has linear effect on ASR distress mitigation and if the dosage of fly ash is more influential than type of fly ash. This research conducted extensive testing with nine different types of fly ashes with three in each category of fly ashes, class $\mathrm{C}$, class $\mathrm{F}$, and intermediate class. The results indicated that the effect of increased dosage of fly ash on ASR mitigation is linear for both low-lime and high-lime fly ashes and the dosage effect is more significant with rapid effect with high-lime fly ashes compared to low-lime fly ashes.
\end{abstract}

\section{Introduction}

The alkali-silica reaction (ASR) related distress is a matter of great concern to the concrete industry and regarded as second most deterioration issue after corrosion. Reactive silica in the presence of alkali in the pore-solution inside the concrete creates a hydrophilic alkali-silica gel, often referred to as ASR gel. Formation of the ASR gel alone does not cause cracking; however when the gel absorbs water, it shows significant potential to swell. The resulting expansion often results in pressures greater than what the concrete can withstand, which in turn causes cracks in the concrete. ASR-induced expansion will occur only if the following three conditions are met: (1) the aggregates in the concrete mixture contain reactive forms of silica, (2) there are sufficient alkalis; alkali content in the cement is greater than $0.60 \%$; and (3) sufficient moisture is available in the hardened concrete (above $75 \% \mathrm{RH}$ within the concrete). Preventing any of these three conditions from being a reality is sufficient to prevent deterioration and is often the emphasis of prevention strategies. Alkalis are present in the cement since cement production involves raw materials that contain alkalis in the range of 0.2 to 1.5 percent of $\mathrm{Na}_{2} \mathrm{O}$. This generates a pore fluid with high $\mathrm{pH}(12.5$ to 13.5). ASTM C150/C150 M-15 [1] designates cements with more than 0.6 percent of $\mathrm{Na}_{2} \mathrm{O}$ as high-alkali cements.

Since the discovery of ASR in concrete in the late 1930s and early 1940s [2], several techniques have been developed and utilized to prevent or minimize the ASR-induced expansion that led to severe distress in concrete structures. Among them, supplementary cementitious materials such as fly ash, meta-kaolin, slag, and silica fume [3-17] are regarded as the most effective ones. This study only focuses on fly ash which is the most commonly used additive to mitigate ASR distress.

Numerous test methods to assess aggregate reactivity have been proposed and standardized in the United States, Canada, Europe, China, Japan, South Africa, and others. Of these, the accelerated mortar bar test (AMBT) (e.g., [1820]), originally proposed by Oberholster and Davis in 1986, has been widely adopted as an accelerated test method for evaluating the alkali-silica reactivity of aggregate for use in concrete [18-22]. On the other hand, the concrete prism test (CPT) (e.g., $[21,23,24])$ is recognized as the most reliable test procedure, which requires at least 1 or 2 years for results depending upon the purpose of the test $[18-21,23,24]$. 
The long duration required in this test method renders this method impractical for use in routine testing and evaluation of aggregate materials. The limitations of the ASTM C1260 [18] and ASTM C1293 [23] test methods have spurred research in the development of new test procedures that are rapid and reliable in evaluating aggregate reactivity and efficacy of ASR mitigation measures. Here, the Miniature Concrete Prism Test was used which is regarded as reliable as ASTM C1293 but produces the result within 56 days.

The combustion of pulverized coal at high temperatures and pressures in power stations produces different types of ash. The "fine" ash fraction is carried upwards with the flue gases and captured before reaching the atmosphere by highly efficient electrostatic precipitators. This material is known as Pulverized Fuel Ash (PFA) or "fly ash." It is composed mainly of extremely fine, glassy spheres and looks similar to cement.

Types of fly ash are as follows:

class $\mathrm{F}$ (less than $6 \%$ lime-calcium oxide, $\mathrm{CaO}$ ), class $\mathrm{C}$ (more than $20 \%$ lime-calcium oxide, $\mathrm{CaO}$ ), intermediate class (lime content between 6\% to 20\%).

Certain mitigation measures are employed to reduce the ASR distress with reactive aggregates [11, 17]. Fly ash (by $\%$ replacement of cement by weight) is widely used in the industry as a mitigation measure. The fly ash in concrete reduces the amount of nondurable calcium hydroxide (lime) and converts lime into calcium silicate hydrate (CSH) over time. Typically class $\mathrm{C}$ fly ashes are not as efficient as class F fly ashes due to their higher calcium oxide content. The increased binding capacity of the hydration products has been linked to the lower $\mathrm{Ca} / \mathrm{Si}$ ratio of the hydrates compared to neat Portland cement pastes [16]. Fly ash is proven to be somewhat variable in its effectiveness on inhibiting alkalisilica reactivity, principally because its composition depends on the coal properties from which it is derived.

A pozzolan is defined by ASTM C618 as a siliceous or siliceous and aluminous material which, in itself, possesses little or no cementitious value but which will, in finely divided form in the presence of moisture, react chemically with calcium hydroxide at ordinary temperature to form compounds possessing cementitious properties.

Pozzolanic reaction stands for a simple acid-base reaction between calcium hydroxide, also known as Portlandite, or $\left(\mathrm{Ca}(\mathrm{OH})_{2}\right)$, and silicic acid $\left(\mathrm{H}_{4} \mathrm{SiO}_{4}\right.$ or $\left.\mathrm{Si}(\mathrm{OH})_{4}\right)$. Simply, this reaction can be summarized in abbreviated notation of cement chemists:

$$
\mathrm{CH}+\mathrm{SH} \longrightarrow \mathrm{C}-\mathrm{S}-\mathrm{H}
$$

\section{Materials and Methods}

2.1. Aggregate. A well-known representative reactive coarse aggregate Spratt limestone was selected with a known nonreactive fine aggregate:

Reactive coarse aggregate: siliceous limestone from Spratt Quarry in Ontario, Canada

Nonreactive fine aggregate: siliceous sand from Dixiana Plant in Pineridge, South Carolina
TABLE 1: Properties of the aggregates used.

\begin{tabular}{lcc}
\hline Property & $\begin{array}{c}\text { Spratt limestone } \\
\text { (coarse aggregate) }\end{array}$ & $\begin{array}{c}\text { Foster Dixiana } \\
\text { (fine aggregate) }\end{array}$ \\
\hline $\mathrm{SG}_{\mathrm{OD}}$ & 2.69 & 2.63 \\
$\mathrm{SG}_{\mathrm{SSD}}$ & 2.71 & 2.64 \\
$\begin{array}{l}\text { Absorption, \% } \\
\begin{array}{l}\text { Dry rodded unit weight } \\
\left(\mathrm{kg} / \mathrm{m}^{3}\right)\end{array}\end{array}$ & $0.46 \%$ & $0.44 \%$ \\
\hline
\end{tabular}

TABLE 2: Chemical composition of high-alkali and low-alkali cement.

\begin{tabular}{lcc}
\hline Oxides (\%) & High-alkali cement & Low-alkali cement \\
\hline $\mathrm{SiO}_{2}$ & 19.78 & 20.6 \\
$\mathrm{Al}_{2} \mathrm{O}_{3}$ & 4.98 & 5.1 \\
$\mathrm{Fe}_{2} \mathrm{O}_{3}$ & 3.13 & 3.4 \\
$\mathrm{CaO}$ & 61.84 & 64.5 \\
$\mathrm{MgO}$ & 2.54 & 1 \\
$\mathrm{SO}_{3}$ & 4.15 & 3.1 \\
$\mathrm{Mn}_{2} \mathrm{O}_{3}$ & - & \\
$\mathrm{Na}_{2} \mathrm{O}$ equivalent & 0.82 & 0.49 \\
Specific gravity & 3.15 & 3.15 \\
\hline
\end{tabular}

The aggregate properties: given in Table 1

Nominal maximum size: 0.5 inches

2.2. Cement. A high-alkali type I cement from Lehigh Cement Company, from Evansville Plant in Pennsylvania, and a low-alkali cement from ARGOS Cement Company from Harleyville, SC, were used in this study. The autoclave expansion of both cements was well below 0.80 percent, at $0.03 \%$ for low-alkali cement and $0.018 \%$ for high-alkali cement. Cement properties are given in Table 2.

2.3. Reagents. Reagent grade sodium hydroxide from Fisher Chemicals was used.

2.4. Fly Ashes. In this research study, nine different fly ashes of varying chemical compositions were used, all at $25 \%$ replacement level of cement by mass. Of the nine fly ashes, three were low-lime ashes (LL1, LL2, and LL3, each with $\mathrm{CaO}$ content less than $8 \%$ ), three were intermediate-lime fly ashes (IL1, IL2, and IL3, each with $\mathrm{CaO}$ content between $8 \%$ and $20 \%$ ), and three were high-lime fly ashes (HL1, HL2, and HL3, each with $\mathrm{CaO}$ content more than $20 \%$ ). For the study involving extended curing duration, only three fly ashes, LL1, IL1, and HL1, were studied. The chemical compositions of these fly ashes are given in Table 3.

2.5. Description of the MCPT Method. In this method, concrete prisms of dimensions $50 \mathrm{~mm} \times 50 \mathrm{~mm} \times 285 \mathrm{~mm}$ ( 2 in. $\times 2$ in. $\times 11.25$ in.) are used for evaluating the reactivity of both coarse and fine aggregates. Mixture proportions of ingredients used in preparing the MCPT specimens are given in Table 4. 
TABLE 3: Chemical composition of fly ashes used in the study.

\begin{tabular}{|c|c|c|c|c|c|c|c|c|}
\hline Fly ashes & $\left(\mathrm{SiO}_{2}\right)(\%)$ & $\left(\mathrm{Al}_{2} \mathrm{O}_{3}\right)(\%)$ & $\left(\mathrm{Fe}_{2} \mathrm{O}_{3}\right)(\%)$ & $(\mathrm{CaO})(\%)$ & $(\mathrm{MgO})(\%)$ & $\left(\mathrm{SO}_{3}\right)(\%)$ & Total alkalis $\left(\right.$ as $\left.\mathrm{Na}_{2} \mathrm{Oe}\right)(\%)$ & Specific gravity \\
\hline LL 1 & 60.30 & 28.60 & 3.20 & 1 & 0.00 & 0.00 & NA & 2.20 \\
\hline LL 2 & 61.63 & 24.86 & 4.56 & 1.4 & 0.23 & 0.21 & NA & 2.09 \\
\hline LL 3 & 57.49 & 29.29 & 2.95 & 6.06 & 1.36 & 0.41 & NA & 1.97 \\
\hline IL 1 & 49.69 & 15.03 & 6.60 & 15.63 & 4.92 & 0.90 & 3.93 & 2.55 \\
\hline IL 2 & 52.40 & 23.20 & 5.73 & 10.33 & 2.08 & 0.64 & 1.90 & 2.26 \\
\hline IL 3 & 41.91 & 21.08 & 5.61 & 18.94 & 4.21 & 0.98 & 2.59 & 2.57 \\
\hline HL 1 & 34.90 & 19.50 & 5.70 & 26.60 & 5.00 & 2.00 & NA & 2.61 \\
\hline HL 2 & 34.55 & 18.10 & 5.68 & 27.50 & 5.04 & 2.80 & 1.83 & 2.63 \\
\hline HL 3 & 31.31 & 18.64 & 5.49 & 29.85 & 5.54 & 2.55 & 2.09 & 2.77 \\
\hline
\end{tabular}

TABLE 4: MCPT specimen mixture proportion.

\begin{tabular}{lc}
\hline Item & Mix proportion \\
\hline Cement content of the mix & $420 \mathrm{~kg} / \mathrm{m}^{3}\left(708 \mathrm{lb} / \mathrm{yd}^{3}\right)$ \\
Water-to-cement ratio & 0.45 \\
Coarse aggregate volume fraction (dry) & 0.65 \\
$\begin{array}{l}\text { Maximum size of coarse aggregate } \\
\text { Coarse aggregate gradation } \\
\text { (\% by weight of total coarse aggregate) }\end{array}$ & $12.5 \mathrm{~mm}(1 / 2 \mathrm{in})$. \\
$12.5 \mathrm{~mm}-9.5 \mathrm{~mm}$ & $57.5 \%$ \\
$9.5 \mathrm{~mm}-4.75 \mathrm{~mm}$ & $42.5 \%$ \\
& $\begin{array}{c}\text { Determined based on ACI } 211 \text { absolute volume method, } \\
\text { Fine aggregate }\end{array}$ \\
& $\begin{array}{c}\text { that is, subtracting the proportions of all the other } \\
\text { ingredients from } 1 \mathrm{~m}^{3} \text { of concrete }\end{array}$ \\
\hline
\end{tabular}

The proportions of aggregate in the $12.5 \mathrm{~mm}-9.5 \mathrm{~mm}$ fraction and the $9.5 \mathrm{~mm}-4.75 \mathrm{~mm}$ fraction were selected, based on the assumption of maintaining approximately constant surface area across each of the two aggregate size fractions.

To ascertain the coarse aggregate reactivity, a nonreactive fine aggregate is used in the concrete mixture to isolate the effects of the reactive aggregate. Similarly, when the reactivity of a fine aggregate is to be ascertained, a nonreactive coarse aggregate is used. In this protocol, a cement having a highalkali content of $0.9 \pm 0.1 \% \mathrm{Na}_{2} \mathrm{O}_{\text {eq. }}$ is required to be used. The alkali content of the concrete is boosted to $1.25 \% \mathrm{Na}_{2} \mathrm{O}_{\text {eq. }}$. by weight of cement similar to the procedure used in the standard ASTM C 1293 test method. The test specimens are demolded 24 hours after casting and after taking the initial length reading the prisms are submerged in water at $60^{\circ}$ Celsius for an additional 24 hours. At the end of 48 hours from the time of casting, the zero-day length change reading is taken, before the prisms are transferred to $1 \mathrm{~N} \mathrm{NaOH}$ soak-solution that has already been preconditioned to $60^{\circ}$ Celsius temperature. Subsequent length change readings are periodically taken at $3,7,10,14,21,28,42,56,70$, and 84 days.

2.6. Modified MCPT Method. In the modified method, the soak-solution, instead of being $1 \mathrm{~N} \mathrm{NaOH}$, matches the poresolution based on the predictive equation described below.
The predicted alkalinity of the pore-solution was calculated based on the equation developed by Stark et al. [25] as follows:

$$
[\mathrm{OH}-]=0.339 \mathrm{Na}_{2} \mathrm{O} \% /(\mathrm{w} / \mathrm{c})+0.022 \pm 0.06 \mathrm{~mol} / \mathrm{L}
$$

Also, 56-day expansion data in each case was taken as the critical percent expansion.

\section{Results and Discussion}

In this study, nine fly ashes of different chemical composition (3 low-lime, 3 intermediate-lime, and 3 high-lime fly ashes) were evaluated at a dosage level of $25 \%$ by mass replacement of cement. These results are shown in Figure 1. It appears from these results that low-lime and intermediate-lime fly ashes were effective in controlling ASR expansion; however highlime fly ashes were not effective in controlling ASR expansion. Figure 2 shows the correlation between the lime content of fly ash and percent expansion at 56 days for the nine fly ashes. It is important to note that the low-lime and the intermediatelime ashes with $\mathrm{CaO}$ content $<15 \%$ mitigated ASR much better than some intermediate-lime and high-lime fly ashes as shown in Figure 2. Beyond the 15\% lime content, there is a steep rise in 56-day percent expansion. Considering the entire range of low- and intermediate-lime fly ashes used in this study (i.e., $\mathrm{CaO} \%$ from $1 \%$ to $19 \%$ ), there is good correlation $\left(R^{2}=0.968\right)$ between lime content of fly ash and the 56day expansion in the MCPT procedure as seen in Figure 3(a). 


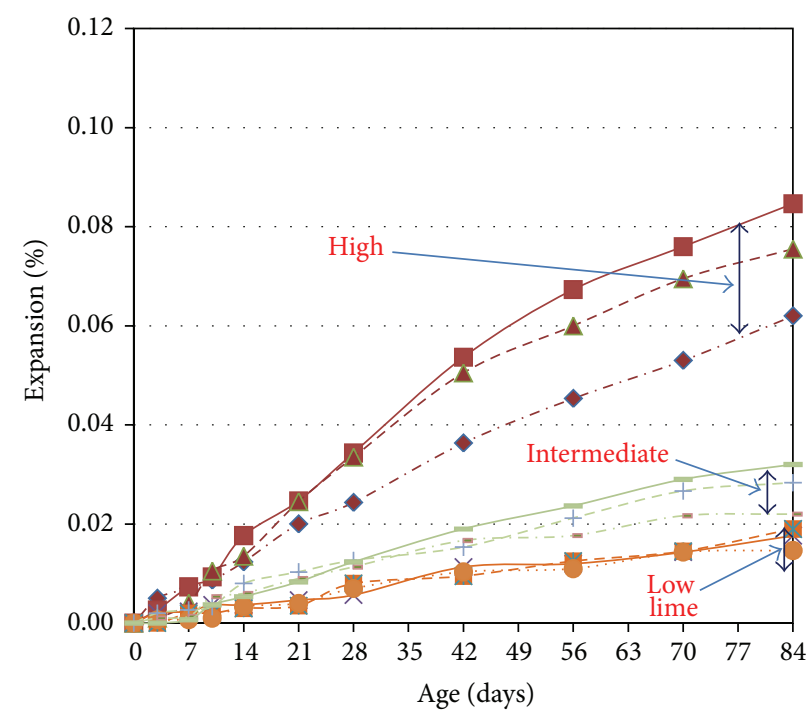

$$
\begin{array}{lll}
\rightarrow-\text { HL-Grd-Gentl } & \cdots \\
\rightarrow-\text { HL-PortNeil } & -+- \text { LL-San Juan } \\
-\star-\text { HL-Comanche } & --- \text { IL-Apache } \\
* \text { LL-NJ } & -- \text { IL-ColetoCreek } \\
- \text { - } & \text { LL-Escalante } &
\end{array}
$$

FIgUre 1: MCPT results for $3 \mathrm{HL}, 3 \mathrm{LL}$, and 3 IL fly ashes (at 25\% dosage with Spratt limestone).

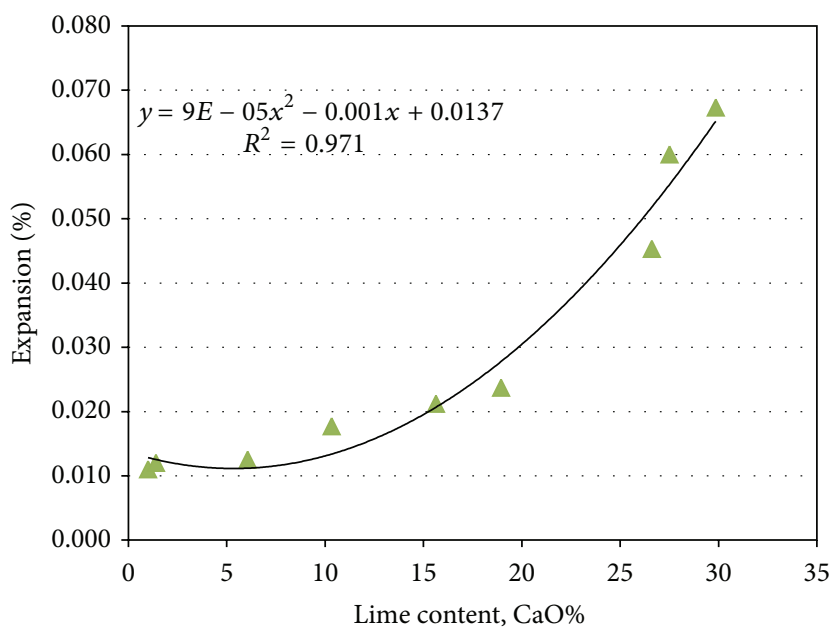

456-day expansion

FIGURE 2: Lime content versus \% expansion at 56 days at 25\% replacement levels for nine fly ashes.

The correlation between lime content and 56-day expansion in MCPT procedure is less than satisfactory when the lime content in fly ashes exceeds $20 \%$ as seen in Figure $3(\mathrm{~b})\left(R^{2}=\right.$ 0.8155).

In order to evaluate the impact of dosage level of fly ash on expansion of concrete prisms in the MCPT method, a limited study was conducted using a low-lime and a high-lime fly ash. In this study, one low-lime (LL1) and one high-lime (HL2) fly ash were used at 15\%, 25\%, and 35\% replacement levels with Spratt limestone as the reactive coarse aggregate. The expansion of MCPT specimens with low-lime fly ash and high-lime fly ash at 15\%,25\%, and 35\% replacement levels is shown in Figures 4 and 5, respectively. Figure 6 shows the relationship between the 56-day MCPT concrete prism expansions and the fly ash replacement level for low-lime and high-lime fly ashes.

Figure 7 and Table 5 show interaction or joint effect of lime content of FA and dosage of FA.

\section{Conclusions}

The conclusions are summarized below:

(I) The effect of increased dosage of fly ash (FA) on ASR mitigation in MCPT method is apparently linear for both low-lime and high-lime (as $\mathrm{CaO} \%$ ) fly ashes. 


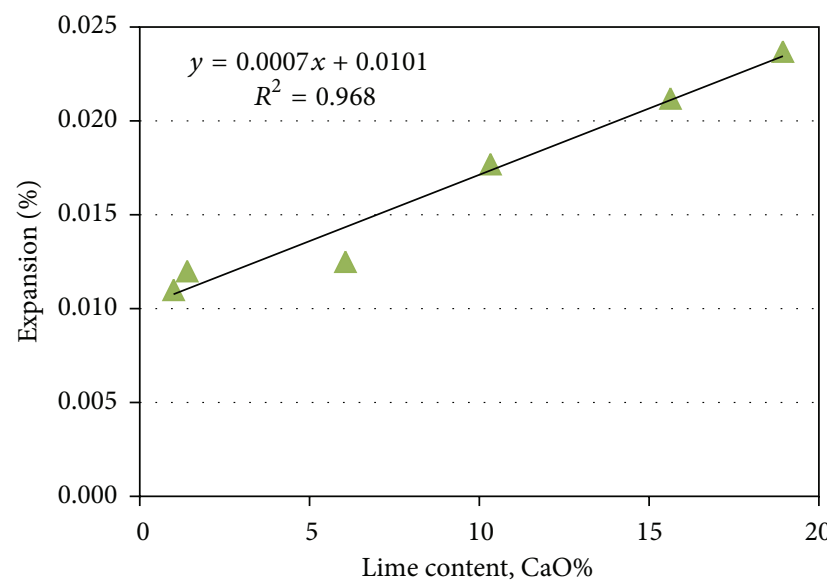

56-day expansion

- Linear (56-day expansion)

(a) Six fly ashes (3 low and 3 intermediate limes)

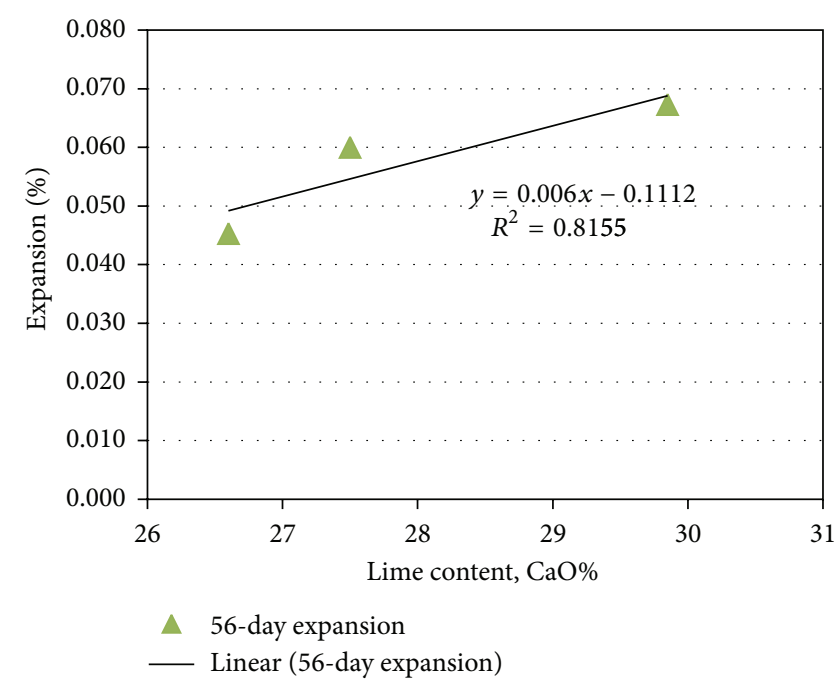

(b) Three high-lime fly ashes

FIGURE 3: Lime content versus \% expansion at 56 days at 25\% replacement levels of fly ash.

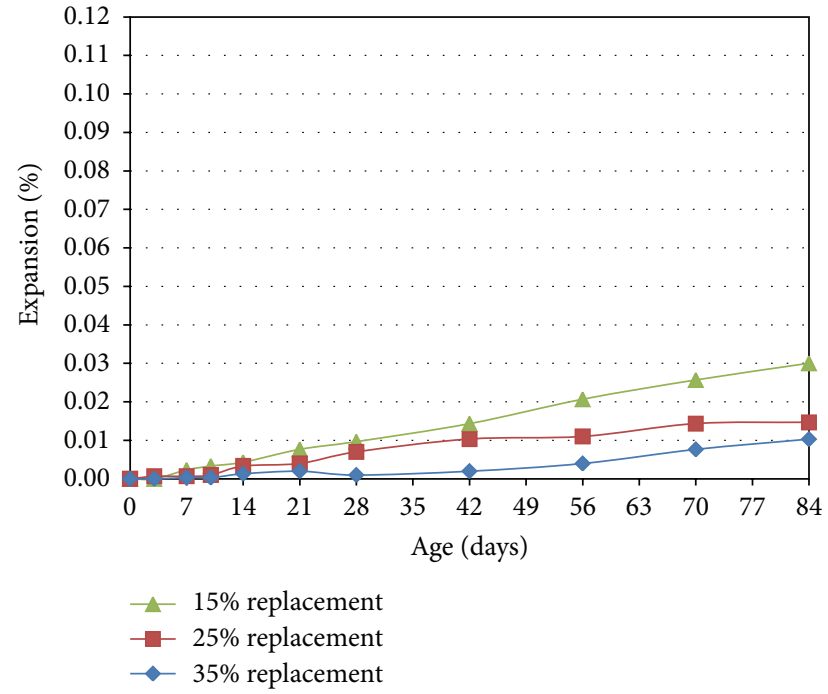

FIGURE 4: MCPT results of Spratt prisms with 15\%, 25\%, and 35\% cement replacement by low-lime fly ash.

TABLE 5: Interaction or joint effect data.

\begin{tabular}{lcc}
\hline & \multicolumn{2}{c}{ FA dosage\% } \\
& $15 \%(-)$ & $35 \%(+)$ \\
\hline $\mathrm{CaO} \%$ of FA, 6.06 (-) & 0.019 & 0.005 \\
$\mathrm{CaO} \%$ of FA, 27.5 (+) & 0.071 & 0.028 \\
& 56-day, \% expansion \\
\hline
\end{tabular}

(II) The replacement dosage effect is more significant, that is, steeper slope, for high-lime fly ashes compared to low-lime fly ashes.

(III) It is interesting to observe that, even at a dosage level of $35 \%$, the high-lime fly ash was ineffective in

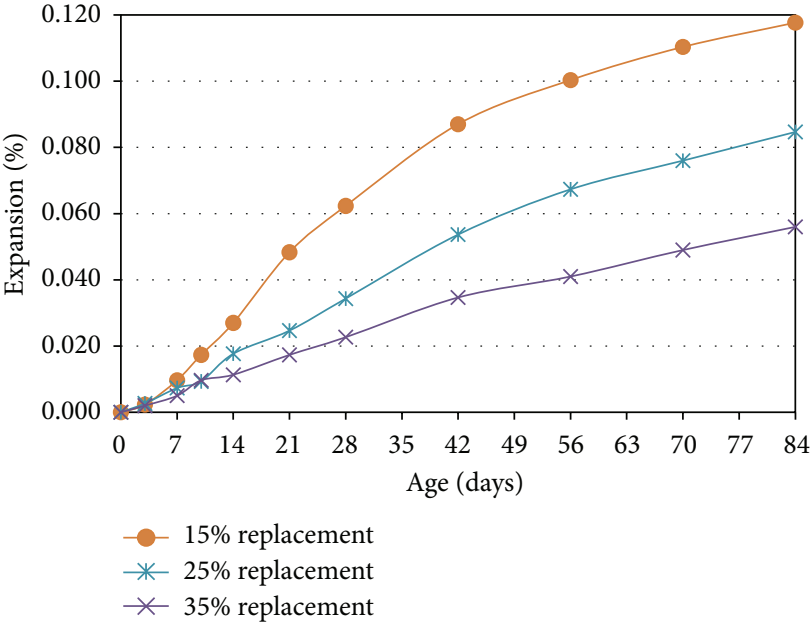

FIGURE 5: MCPT results of Spratt prisms with 15\%, 25\%, and 35\% cement replacement by high-lime fly ash.

mitigating the expansions in the highly reactive environment such as using Spratt limestone aggregate.

(IV) The low-lime fly ash was effective even at a cement replacement level of $25 \%$ by mass for the highly reactive aggregate.

(V) Lime content versus ASR induced expansion has linear relationship for the class $\mathrm{F}$ through intermediatelime fly ash and separately for the range of class $\mathrm{C}$ fly ash, but the relationship is not linear but rather curved for the whole range of lime content.

(VI) There is an interaction or joint effect between FA dosage and lime content $(\mathrm{CaO} \%)$ of fly ash, which is, increase in FA dosage (\%) reduces the ASR expansion more rapidly in high-lime FA than low-lime FA. 


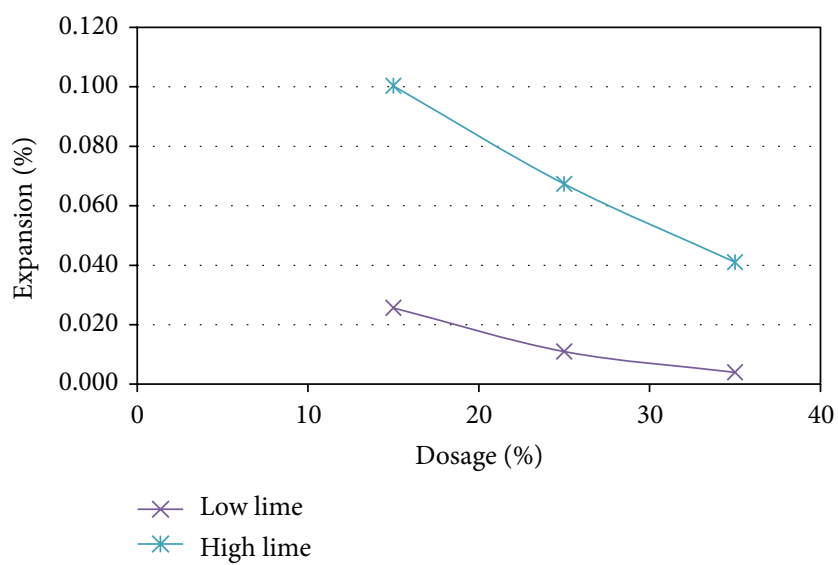

FIGURE 6: Relationship between the 56-day MCPT concrete prism expansions and the fly ash replacement levels for low-lime and high-lime fly ashes.

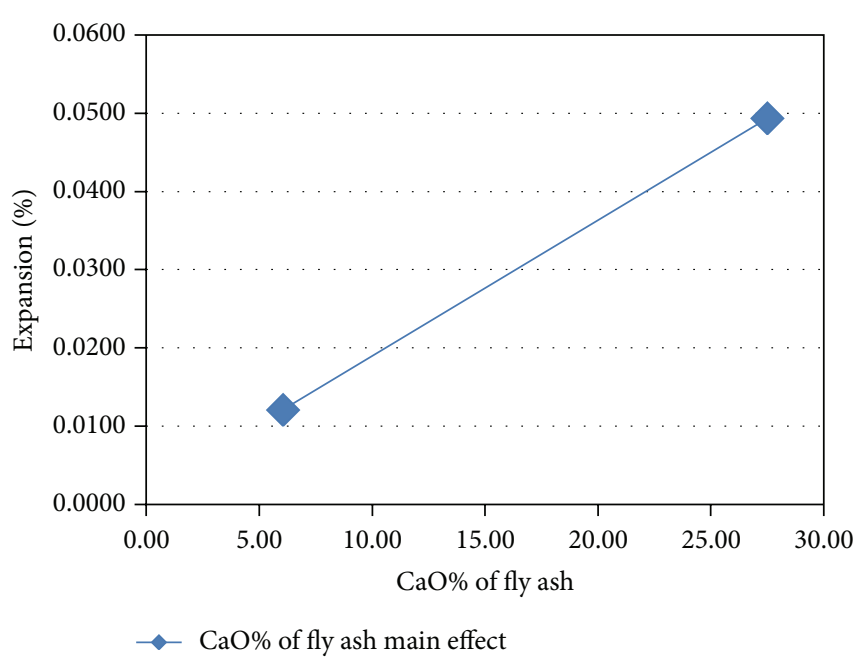

(a) Main effect

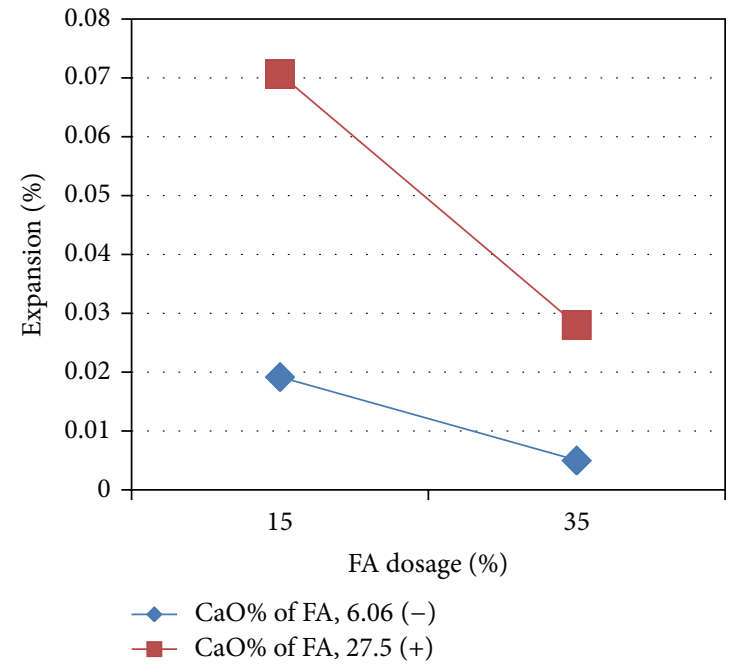

(b) Interaction or joint effect

Figure 7: Main effect of lime content (CaO\%) of fly ash and interaction or joint effect of lime content of FA and dosage of FA.

\section{Competing Interests}

The author certifies that he is not affiliated with or involved in any organization or entity with any financial interests (such as honoraria, educational grants, membership, employment, consultancies, stock ownership, or other equity interests and expert testimony or patent-licensing arrangements) or nonfinancial interests (such as personal or professional relationships, etc.) in the subject matter or materials discussed in this manuscript.

\section{Acknowledgments}

The author gratefully acknowledges the guidance of his Ph.D. advisor, Dr. Rangaraju of Clemson University, Clemson, SC, USA.

\section{References}

[1] ASTM C150/C150M-15, Standard Specification for Portland Cement, ASTM International, West Conshohocken, Pa, USA, 2016.
[2] T. E. Stanton, "Expansion of concrete through reaction between cement and aggregate," Proceeding American Society of Civil Engineering, vol. 66, no. 10, pp. 1781-1811, 1940.

[3] E. R. Latifee and P. R. Rangaraju, "Miniature concrete prism test: rapid test method for evaluating alkali-silica reactivity of aggregates," Journal of Materials in Civil Engineering, vol. 27, no. 7, Article ID 04014215, 2015.

[4] S. M. H. Shafaatian, A. Akhavan, H. Maraghechi, and F. Rajabipour, "How does fly ash mitigate alkali-silica reaction (ASR) in accelerated mortar bar test (ASTM C1567)?" Cement and Concrete Composites, vol. 37, no. 1, pp. 143-153, 2013.

[5] T. Uygunoğlu, I. B. Topcu, O. Gencel, and W. Brostow, “The effect of fly ash content and types of aggregates on the properties of pre-fabricated concrete interlocking blocks (PCIBs)," Construction and Building Materials, vol. 30, pp. 180-187, 2012.

[6] M. D. A. Thomas, "Field studies of fly ash concrete structures containing reactive aggregates," Magazine of Concrete Research, vol. 48, no. 177, pp. 265-279, 1996.

[7] A. Beglarigale and H. Yazici, "Mitigation of detrimental effects of alkali-silica reaction in cement-based composites by combination of steel microfibers and ground-granulated blast-furnace 
slag," Journal of Materials in Civil Engineering, vol. 26, no. 12, Article ID 04014091, 2014.

[8] K. Pettersson, "Effects of silica fume on alkali-silica expansion in mortar specimens," Cement and Concrete Research, vol. 22, no. 1, pp. 15-22, 1992.

[9] T. C. Esteves, R. Rajamma, D. Soares, A. S. Silva, V. M. Ferreira, and J. A. Labrincha, "Use of biomass fly ash for mitigation of alkali-silica reaction of cement mortars," Construction and Building Materials, vol. 26, no. 1, pp. 687-693, 2012.

[10] K. J. Folliard, R. Barborak, T. Drimalas et al., "Preventing ASR/DEF in new concrete," Final Report FHWA/TX-06/04085-5, Center for Transportation Research at the University of Texas at Austin, 2006.

[11] P. P. Hudec and N. K. Banahene, "Chemical treatments and additives for controlling alkali reactivity," Cement and Concrete Composites, vol. 15, no. 1-2, pp. 21-26, 1993.

[12] L. J. Malvar and L. R. Lenke, "Efficiency of fly ash in mitigating alkali-silica reaction based on chemical composition," ACI Materials Journal, vol. 103, no. 5, pp. 319-326, 2006.

[13] L. J. Malvar, G. D. Cline, D. F. Burke, R. Rollings, T. W. Sherman, and J. Greene, "Alkali silica reaction mitigation: state-of-the-art and recommendations," ACI Materials Journal, vol. 99, no. 5, pp. 480-489, 2002.

[14] R. D. Moser, A. R. Jayapalan, V. Y. Garas, and K. E. Kurtis, "Assessment of binary and ternary blends of metakaolin and Class C fly ash for alkali-silica reaction mitigation in concrete," Cement and Concrete Research, vol. 40, no. 12, pp. 1664-1672, 2010.

[15] M. Thomas, "The effect of supplementary cementing materials on alkali-silica reaction: a review," Cement and Concrete Research, vol. 41, no. 12, pp. 1224-1231, 2011.

[16] M. D. A. Thomas, M. H. Shehata, and S. G. Shashiprakash, "The use of fly ash in concrete: classification by composition," Cement, Concrete, and Aggregates, vol. 21, no. 2, pp. 105-110, 1999.

[17] E. W. Touma, D. W. Fowler, and R. L. Carrasquillo, "Alkalisilica reaction in Portland cement concrete: testing methods alternatives," Research Report ICAR 301, International Center for Aggregates Research (ICAR), 2001.

[18] ASTM, "Standard test method for potential alkali reactivity of aggregates (Mortar-Bar method)," ASTM C1260, ASTM, West Conshohocken, Pa, USA, 2007.

[19] Canadian Standards Association, Test Method for Detection of Alkali-silica Reactive Aggregate by Accelerated Expansion of Mortar Bars, A23.2-25A, Canadian Standards Association, Toronto, Canada, 1994.

[20] RILEM Recommended Test Method AAR-2, "Detection of potential alkali-reactivity of aggregates-the ultra-accelerated mortar-bar test," Materials and Structures, vol. 33, no. 5, pp. 283289, 2000.

[21] Canadian Standards Association, Potential Expansivity of Aggregates; Procedure for Length Change Due to Alkali-Aggregate Reaction in Concrete Prisms, A23.2-14A, Canadian Standards Association, Toronto, Canada, 1994.

[22] G. Davies and R. E. Oberholster, "An accelerated method for testing the potential alkali reactivity of siliceous aggregates," Cement and Concrete Research, vol. 16, no. 2, pp. 181-189, 1986.

[23] ASTM, "Standard test method for concrete aggregates by determination of length change of concrete due to alkali-silica reaction," ASTM C1293, ASTM, West Conshohocken, Pa, USA, 2007.
[24] RILEM Recommended Test Method AAR-3, "Detection of potential alkali-reactivity of aggregates-method for aggregate combinations using concrete prisms," Materials and Structures, vol. 33, no. 229, pp. 290-293, 2000.

[25] D. Stark, S. Diamond, and M. Moranville-Regourd, Alkali-Silica Reactivity: An Overview of Research, SHRP-C-342, Strategic Highway Research Program, Washington, DC, USA, 1993. 

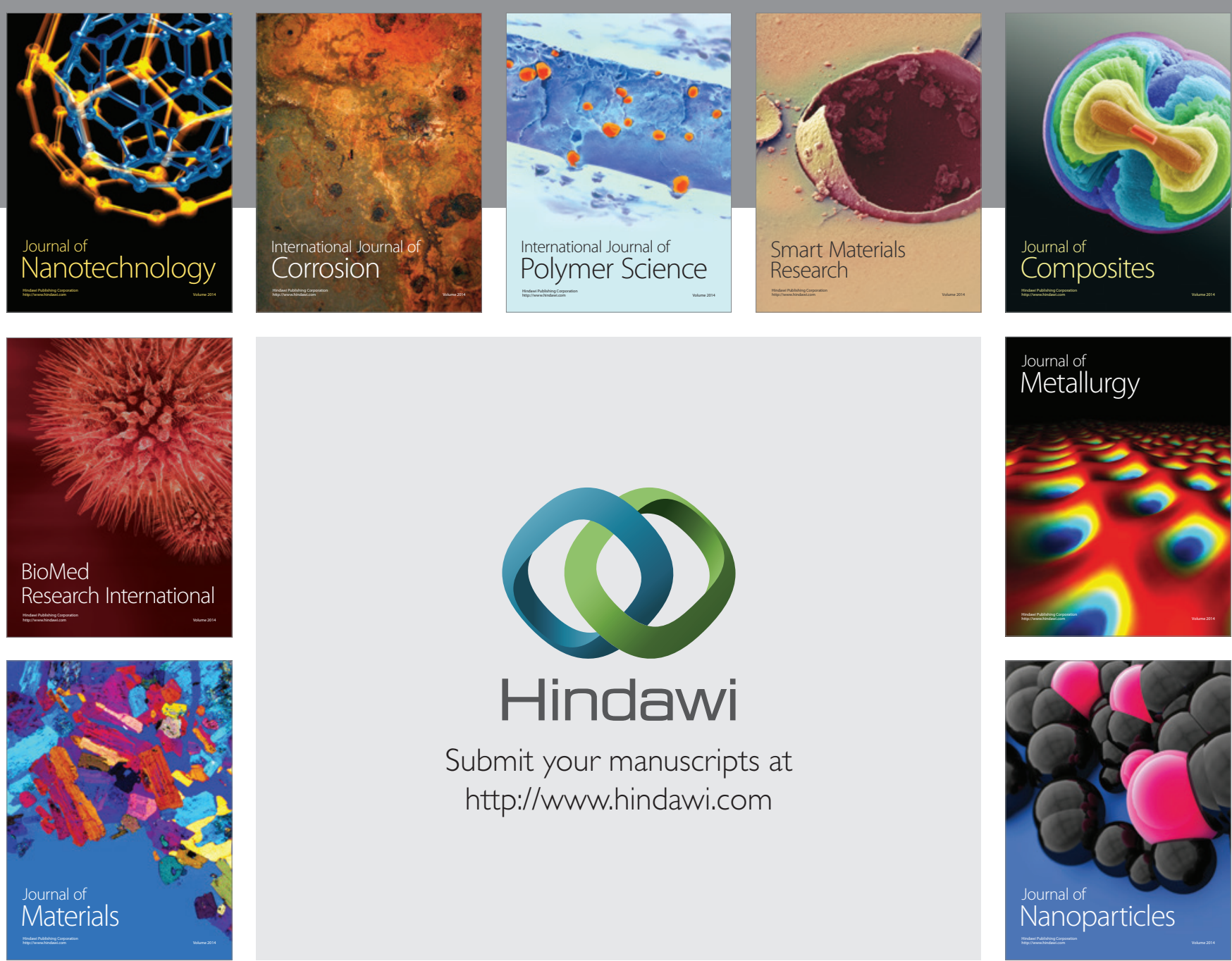

\section{Hindawi}

Submit your manuscripts at

http://www.hindawi.com

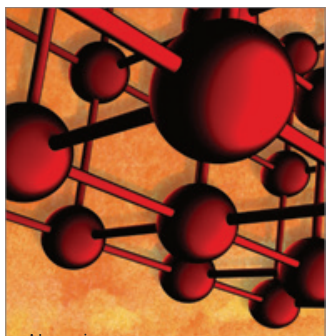

Materials Science and Engineering
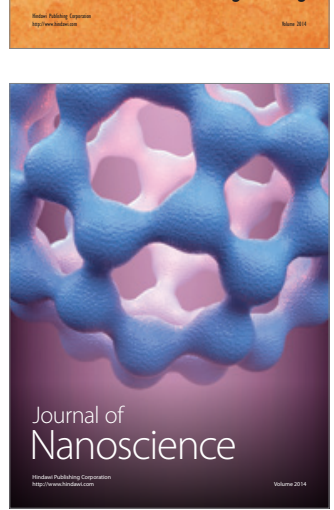
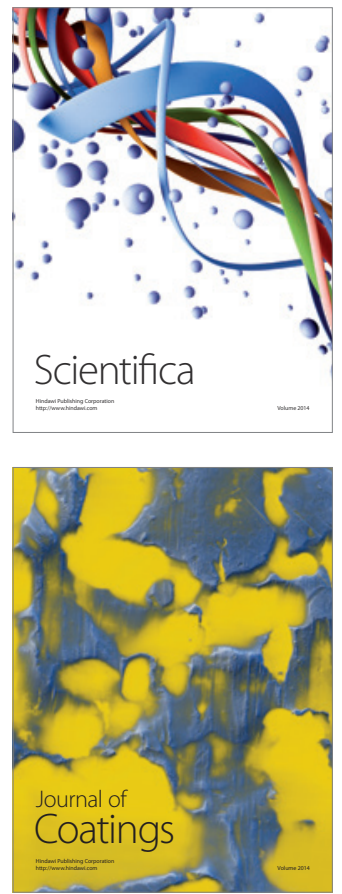
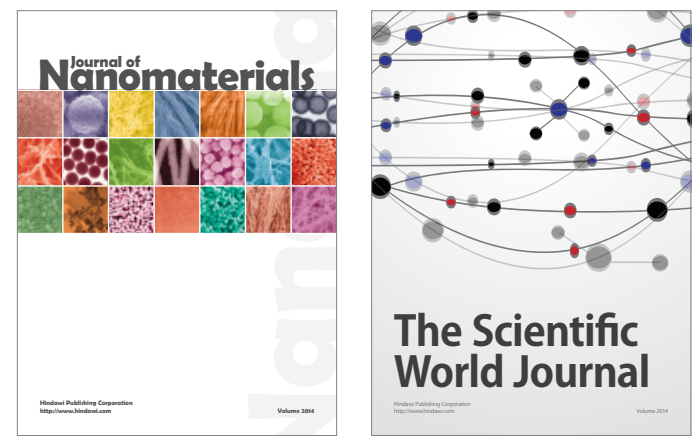

The Scientific World Journal
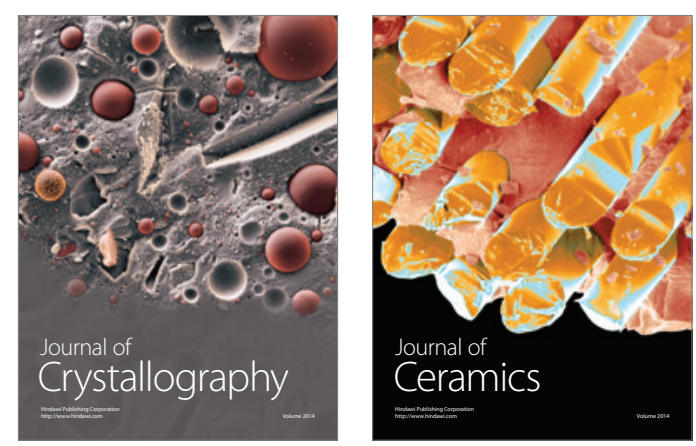
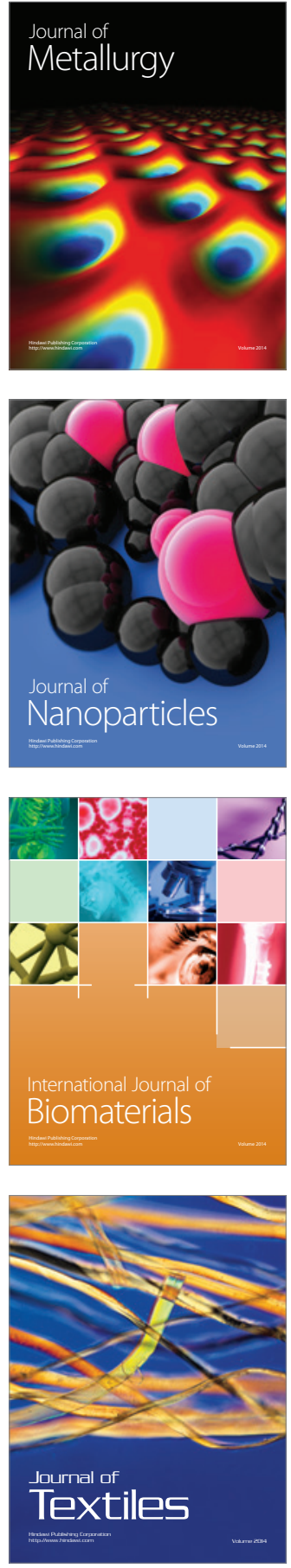